\title{
Vagal Afferent Pathway Mediates Physiological Action of Cholecystokinin on Pancreatic Enzyme Secretion
}

\author{
Ying Li and Chung Owyang \\ The University of Michigan Medical Center, Gastroenterology Research Unit, Department of Internal Medicine, Ann Arbor, \\ Michigan 48109
}

\begin{abstract}
To establish the mechanism(s) and site(s) of action of cholecystokinin (CCK) on pancreatic secretion under physiological conditions, we used an in vivo model using anesthetized rats with pancreaticobiliary cannulas. Infusion of CCK-8 (10-160 pmol / kg per $h$ ) produced a dose-dependent increase in plasma CCK levels. CCK-8 infusion at $40 \mathrm{pmol} / \mathrm{kg}$ per $\mathrm{h}$ produced a plasma CCK level of 7.9 $\pm 1.5 \mathrm{pM}$ and an $80 \%$ increase in pancreatic protein output over basal. This level was closely approximated by a postprandial peak plasma CCK level by $6.2 \pm 1.1$ pM. Pretreatment with atropine or hexamethonium completely abolished pancreatic protein response to low doses of CCK-8 (10-40 $\mathrm{pmol} / \mathrm{kg}$ per $\mathrm{h}$ ) but had only partial effect on doses $>40 \mathrm{pmol} / \mathrm{kg}$ per $\mathrm{h}$. Bilateral vagotomy also abolished the pancreatic responses to low doses of CCK-8. Similarly perivagal treatment with a sensory neurotoxin, capsaicin, caused a complete inhibition of pancreatic protein secretion in response to CCK-8 infusion. In contrast, pancreatic protein responses to bethanechol were similar in control and capsaicin-treated rats. In separate studies we demonstrated that gastroduodenal but not jejunal application of capsaicin for $30 \mathrm{~min}$ abolished pancreatic protein secretion in response to physiological doses of CCK-8. In conclusion, $\mathrm{CCK}$ at physiological levels stimulates pancreatic enzyme secretion via a capsaicin-sensitive afferent vagal pathway originating from the gastroduodenal mucosa. $(J$. Clin. Invest. 1993. 92:418-424.) Key words: cholecystokinin • vagal afferent pathway • pancreatic secretion • capsaicin • atropine $\bullet$ vagotomy
\end{abstract}

\section{Introduction}

Cholecystokinin (CCK) is the major mediator of pancreatic exocrine secretion. The mechanism(s) responsible for CCK-induced pancreatic enzyme secretion under physiological conditions however is unclear. In vitro studies using dispersed pancreatic acini demonstrate that CCK-stimulated amylase release is insensitive to atropine or tetrodotoxin (TTX), ${ }^{1}$ indicating direct action on pancreatic acini (1). Furthermore, the effects of cholinergic agonists and CCK in isolated pancreatic acini

Address reprint requests to Chung Owyang, M.D., 3912 Taubman Center, Box 0362, The University of Michigan Medical Center, Ann Arbor, MI 48109.

Received for publication 21 December 1992.

1. Abbreviations used in this paper: 2DG, 2-deoxy-D-glucose; TTX, tetrodotoxin.

J. Clin. Invest.

(C) The American Society for Clinical Investigation, Inc.

0021-9738/93/07/418/07 $\$ 2.00$

Volume 92, July 1993, 418-424 preparations are no more than additive $(1,2)$. This suggests the effect of CCK on enzyme secretion is cholinergically independent $(3,4)$. However, in vivo studies in humans (5-7) and dogs $(8,9)$ show that pancreatic secretion stimulated by CCK can be blocked by atropine, suggesting action via cholinergic pathways. Furthermore, enzyme output in patients after vagotomy in response to low doses of CCK is reduced compared with normal controls (10). It appears therefore that CCK can act via both atropine-sensitive neural pathways to stimulate pancreatic exocrine secretion. Currently, it is not known if exogenous CCK infusions that produce physiological levels stimulate pancreatic secretion via cholinergic or noncholinergic pathways. This issue has important physiological ramifications. If CCK at physiological levels stimulates pancreatic secretion via an atropine-sensitive pathway, then cholinergic neural pathways rather than pancreatic acinar cells represent the primary targets on which CCK may act as a major mediator of postprandial pancreatic enzyme secretion.

In this study we investigated the mechanism and site of action of CCK on pancreatic enzyme secretion under physiological conditions using an in vivo rat model. We hypothesize that CCK at physiological levels acts via stimulation of cholinergic pathways whereas supraphysiological CCK levels act directly on pancreatic acini. Furthermore, since recent studies in the rats demonstrate that afferent fibers of the abdominal vagus mediate CCK-elicited satiety signals (11), we examined the role of vagal afferent pathways in the mediation of CCK's action on pancreatic enzyme secretion. Chemical ablation studies were also performed to identify specific vagal branches that are involved in this function.

\section{Methods}

\section{Materials}

The following were purchased from Sigma Chemical Co. (St. Louis, MO) atropine sulfate, bethanechol chloride, 2-deoxy-D-glucose (2DG), and capsaicin. Octapeptide of cholecystokinin was purchased from Peninsula Laboratories Inc. (Belmont, CA).

\section{Experimental procedures}

Animal preparation. Male Sprague-Dawley rats, weighing between 250 and $300 \mathrm{~g}$, were fasted overnight and anesthetized with a mixture of xylazine and ketamine (13 and $87 \mathrm{mg} / \mathrm{kg}$ body wt, respectively). Through a midline incision, a polyethylene catheter was inserted into the common bile-pancreatic duct at the ampulla. A second catheter was placed into the duodenum, slightly above the sphincter of Oddi for intestinal perfusion of pancreaticobiliary juice. The abdominal wound was covered with a saline gauge and the animal was maintained at $37^{\circ} \mathrm{C}$ with a heating pad.

Pancreatic secretion study. After 60 min of stabilization, combined bile-pancreatic secretions were collected every $15 \mathrm{~min}$. The volume was measured and an aliquot was taken and diluted with distilled water for protein determination. The remainder of the undiluted bile pancreatic juice was returned to the intestine via the duodenal cannula during the 
next collection period. Pancreaticobiliary juice protein was measured spectrophotometrically using the assay method of Bradford (12). Our previous study (13) confirmed that the increase in protein output in the bile pancreatic juice after CCK-8 stimulation mainly reflected protein from the pancreatic source. Biliary juice protein did not increase with CCK stimulation.

CCK-8 dose-response studies. Graded doses of CCK-8 (10-160 $\mathrm{pmol} / \mathrm{kg}$ per $\mathrm{h}$ ) were infused for $60 \mathrm{~min}$. Six rats were tested for each dose. Pancreaticobiliary juice was collected every $15 \mathrm{~min}$. Blood samples for CCK measurement were obtained at the end of each infusion by cardiac puncture. Plasma CCK levels were measured by a bioassay method previously reported (14). In separate studies, postprandial plasma CCK response was determined by obtaining blood samples from rats fed $5 \mathrm{ml}$ of $18 \%$ casein. Casein was instilled into the stomach with an orogastric tube and blood samples were obtained $15 \mathrm{~min}$ after casein administration.

Atropine, hexamethonium, and TTX infusion studies. To determine the role of cholinergic pathways in the mediation of CCK's action, atropine $(100 \mu \mathrm{g} / \mathrm{kg}$ per h$)$ was infused $30 \mathrm{~min}$ before infusion of CCK-8 and was administered throughout the remainder of the experiment. Pancreatic protein outputs and plasma CCK levels were compared with those obtained without atropine. Similar studies were performed with hexamethonium treatment $(15 \mathrm{mg} / \mathrm{kg}$ bolus plus $7.5 \mathrm{mg} /$ $\mathrm{kg}$ per $\mathrm{h}$ continuous infusion) to determine the role of presynaptic cholinergic neurons in the mediation of CCK-stimulated pancreatic enzyme secretion.

To exert total neural blockade, TTX, a nonspecific blocker of neuronal axonal transmission, was administered by regional intraarterial infusion into the pancreatic artery through the abdominal aorta with the ligation of the renal arteries and temporary blockade of the iliac bifurcation. A loading dose of $10 \mu \mathrm{g} / \mathrm{kg}$ TTX was given followed by $2 \mu \mathrm{g} / \mathrm{kg}$ per $h$ of continuous infusion throughout the experiment. A tracheal cannula was inserted to secure free airways and the rats were artificially ventilated. Complete neural blockade was established by demonstrating that pancreatic secretion in response to 2DG stimulation was completely abolished but responses to bethanechol remained unaffected.

Bilateral subdiaphragmatic vagotomy. To demonstrate that physiological levels of plasma CCK act via stimulation of the vagal pathways, acute bilateral subdiaphragmatic vagotomy was performed. Through a midline incision of the abdominal wall, the stomach was carefully manipulated to expose the esophagus. The subdiaphragmatic vagal trunks were exposed halfway between the diaphragm and the gastric cardia. Both anterior and posterior trunks of the vagal nerves were transected. For control experiments, the abdominal vagal nerves were exposed but not cut. CCK dose-response studies were performed as described. To demonstrate completeness of vagotomy, pancreatic protein secretion in response to 2DG was tested. 2DG, a nonmetabolicable glucose analogue, causes hypothalamia, glucopenia, and excites the dorsal vagal nuclei. It has traditionally been used as an agent for testing completeness of vagotomy $(15,16)$. A dose of $75 \mathrm{mg} / \mathrm{kg}$ i.v. was used.

Perivagal application of capsaicin. To investigate the role of vagal afferent pathway in the mediation of CCK's action, we examined the effects of perivagal application of capsaicin. After anesthesia the abdominal vagal trunks were exposed. A small piece of gauze soaked in 0.1 capsaicin solution $(0.1 \mathrm{ml}$ per rat $)$ was left on the vagal trunks for 30 $\mathrm{min}$. Solutions of vehicle alone were applied to control rats. CCK doseresponse studies as described above were performed $5 \mathrm{~d}$ after surgery in these two groups of rats.

Vagal afferent rootlet section. To further demonstrate that vagal afferent pathway mediates CCK's action on pancreatic enzyme secretion, parallel studies with vagal afferent rootlet section were performed. In the rats selective afferent or efferent rootlet section is possible because the afferent rootlet enters the medulla dorsal to the site where efferent rootlet exists. The rats were placed in a head holder with the aid of an operating microscopy and the basal aspect of the occipital bone was exposed by postauricular scalp incision. This revealed the vagus nerve as it penetrated through the duramater and separated into afferent and efferent groups of rootlets. The vagal afferent group consists of two to four rootlets that reach the dorsal lateral surface of the medulla. Through the dorsal approach the afferent rootlets were exposed directly and transected under direct vision. In the control group, craniotomy was performed in sham operations but rootlet sections were not performed. $2 \mathrm{~d}$ after left vagal afferent rootlet section, a right cervical vagotomy was performed before CCK dose-response studies.

Gastroduodenal mucosal application of capsaicin. To investigate if the CCK-sensitive afferent nerve endings originate from the gastroduodenal mucosa, we examined the effects of mucosal application of capsaicin in the stomach and duodenum (17). Capsaicin was also applied to the jejunum to examine regional specificity. After laparotomy, capsaicin $(6 \mathrm{mg} / \mathrm{ml})$ was topically applied to the gastroduodenal or jejunal mucosa for $30 \mathrm{~min}$. Saline application was used in control rats. CCK dose-response studies were performed $4 \mathrm{~d}$ after local capsaicin application. Rats were checked for normal eye wiping movement, which indicates that local mucosal treatment of capsaicin has no systemic effect (17).

Bethanechol and CCK interaction studies. To investigate if the stimulatory action of CCK requires the presence of a cholinergic tone, we examined the effect of bethanechol, a muscarinic receptor agonist, on CCK-evoked pancreatic secretion in vagotomized rats. Acute subdiaphragmatic vagotomy was performed as described above in two groups of rats. In the first group of rats, which served as the control, after a 60-min basal period, pancreatic protein secretion in response to intravenous infusion of bethanechol $(0.5 \mathrm{mg} / \mathrm{kg}$ per $\mathrm{h})$ was measured for a total of $120 \mathrm{~min}$. The second group of rats received intravenous infusion of CCK-8 ( $40 \mathrm{pmol} / \mathrm{kg}$ per $\mathrm{h}$ ) alone for $30 \mathrm{~min}$ followed by concurrent intravenous administration of bethanechol $(0.5 \mathrm{mg} / \mathrm{kg}$ per $\mathrm{h})$ for an additional $120 \mathrm{~min}$.

\section{Statistical analysis}

Results were expressed as mean $\pm \mathrm{SE}$. The multivariate analysis of variance method was used to evaluate the effect of the repeated measurement over time, treatment effect, and the interaction between them. Significance was accepted at the $5 \%$ level.

\section{Results}

\section{Plasma CCK levels}

After a 12-h fast, the basal plasma CCK levels were $0.5 \pm 0.1$ $\mathrm{pM}$. The basal levels were not affected by vagotomy $(0.6 \pm 0.1$ $\mathrm{pM})$ or atropine administration $(0.55 \pm 0.09 \mathrm{pM})$. Intravenous infusion of CCK produced a dose-related increase in plasma CCK levels (Fig. 1). The plasma CCK levels during infusion of 40 and $160 \mathrm{pmol} / \mathrm{kg}$ per $\mathrm{h}$ were $7.9 \pm 0.5$ and $19 \pm 2.5 \mathrm{pM}$, respectively. Plasma CCK responses to CCK infusion were not affected by bilateral vagotomy (Fig. 1) or atropine administration (data not shown).

To determine which rate of CCK-8 infusion would produce a physiological plasma CCK level, we measured plasma CCK levels after administration of a casein meal. Casein feeding resulted in a postprandial peak increase in plasma CCK levels to $7.3 \pm 1.1 \mathrm{pM}$ (Fig. 1). Therefore it appears that the infusion of CCK-8 at $40 \mathrm{pmol} / \mathrm{kg}$ per $\mathrm{h}$ produced a plasma CCK level $(7.9 \pm 0.5 \mathrm{pM})$ similar to that seen physiologically after a casein meal $(7.3 \pm 1.1 \mathrm{pM})$. In contrast, the 80 and $160 \mathrm{pmol} / \mathrm{kg}$ per $\mathrm{h}$ doses produced markedly supraphysiological plasma CCK levels (Fig. 1).

\section{Pancreatic secretion studies}

The basal pancreatic protein secretion was stable, averaging $130 \pm 18 \mathrm{mg} / \mathrm{h}$. Intravenous infusion of CCK-8 produced a dose-dependent increase in pancreatic protein secretion (Fig. 2). CCK-8 infusion of $40 \mathrm{pmol} / \mathrm{kg}$ per $\mathrm{h}$, which produced a plasma CCK level similar to the postprandial peak plasma 


\section{Plasma CCK Response}

Exogenous CCK Infusion

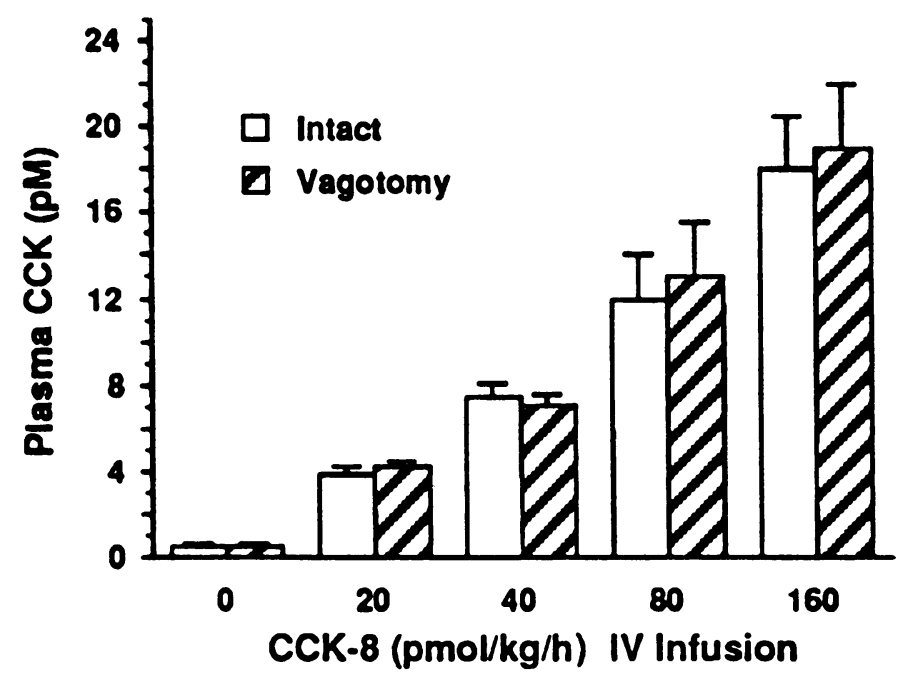

Casein Feeding

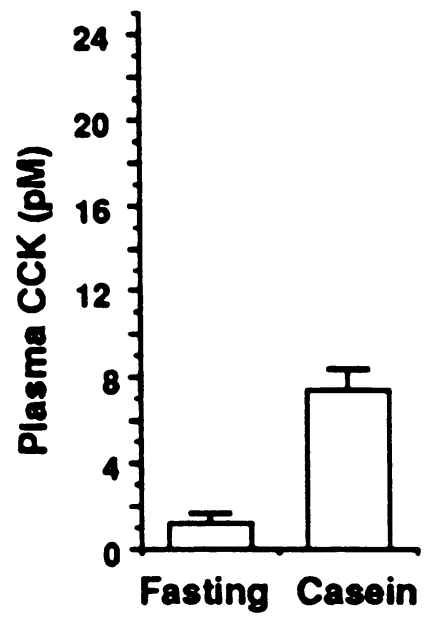

Figure 1. Infusion of cholecystokinin octapeptide $(C C K-8)$ induced dose-dependent increase in plasma CCK levels. Infusion of CCK-8 at $40 \mathrm{pmol} / \mathrm{kg}$ per $\mathrm{h}$ produced plasma levels similar to those seen after a casein meal. Vagotomy had no effect on basal and CCK-8 infusion-stimulated plasma CCK levels. Values are mean \pm SE for six rats in each group. level, caused an $80 \%$ increase in pancreatic protein output over basal (Fig. 2). On the other hand, infusion of supraphysiological doses of CCK-8 at 80 and $160 \mathrm{pmol} / \mathrm{kg}$ per h produced an 180 and $238 \%$ increase in pancreatic protein output over basal (Fig. 2).

Effect of atropine and hexamethonium. Administration of atropine ( $100 \mu \mathrm{g} / \mathrm{kg}$ per $\mathrm{h}$ ) or hexamethonium ( $15 \mathrm{mg} / \mathrm{kg}$ followed by $7.5 \mathrm{mg} / \mathrm{kg}$ per hr) did not affect basal pancreatic output but completely abolished pancreatic responses to CCK8 infusion at 10,20, and $40 \mathrm{pmol} / \mathrm{kg}$ per h (Fig. 2). In contrast, atropine or hexamethonium produced only partial or no inhibi-

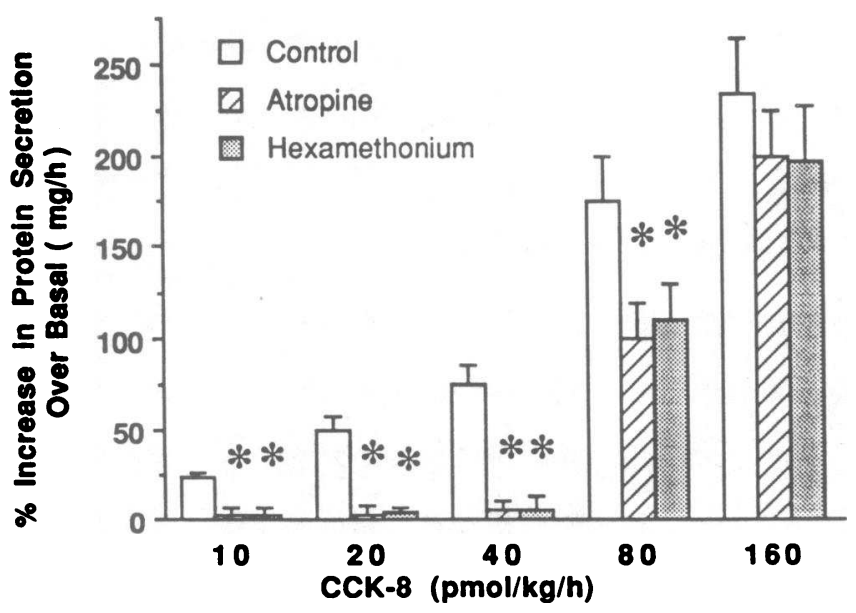

Figure 2. CCK-8 infusion evoked a dose-dependent increase in pancreatic protein secretion. Doses $>40 \mathrm{pmol} / \mathrm{kg}$ per $\mathrm{h}$ are considered supraphysiological. Administration of atropine $(100 \mu \mathrm{g} / \mathrm{kg} \mathrm{per} \mathrm{h})$ and hexamethonium $(15 \mathrm{mg} / \mathrm{kg}+7.5 \mathrm{mg} / \mathrm{kg}$ per $\mathrm{h})$ completely abolished pancreatic responses to physiological doses of CCK-8 ( $\leq 40 \mathrm{pmol} / \mathrm{kg}$ per $h$ ) but were much less potent at higher CCK-8 doses (80-160 $\mathrm{pmol} / \mathrm{kg}$ per $\mathrm{h})$. Values are mean $\pm \mathrm{SE}$ for six rats in each group. ${ }^{*} P$ $<0.05$. tion of pancreatic responses to supraphysiological doses of CCK-8 (Fig. 2). These observations indicate that at physiological levels, CCK acts at a presynaptic site of the cholinergic pathway, whereas at supraphysiological levels CCK acts mainly via an atropine-insensitive pathway.

Effect of vagotomy. Immediately after vagotomy there was no change in basal pancreatic protein secretion. However, the responses to physiological doses of CCK-8 (10,20, and 40 $\mathrm{pmol} / \mathrm{kg}$ per $\mathrm{h}$ ) were completely abolished (Fig. 3 ). This suggests that the vagal pathway is the primary site of action of CCK under physiological conditions. In contrast, vagotomy

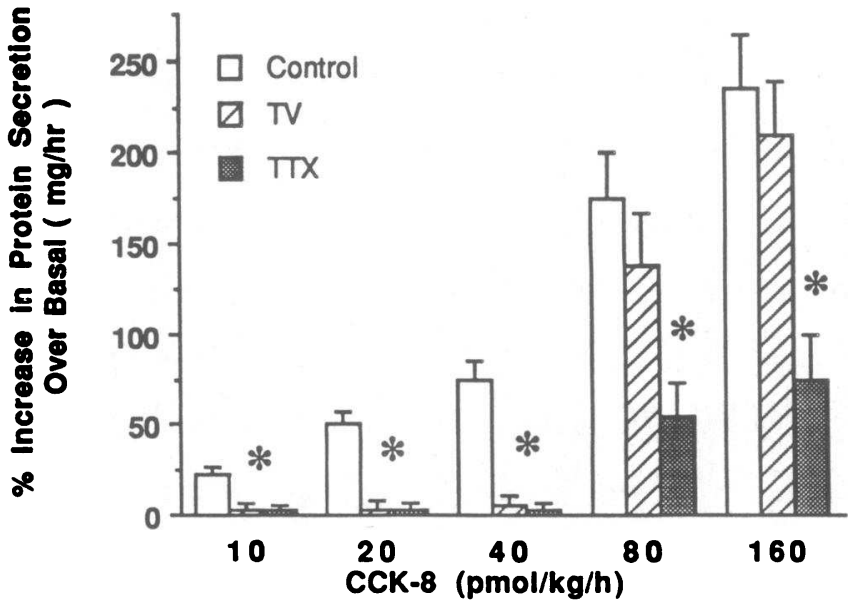

Figure 3. Immediately after vagotomy $(T V)$ there was no change in basal pancreatic protein secretion but the responses to physiological doses $(\leq 40 \mathrm{pmol} / \mathrm{kg} / \mathrm{hr}$ ) of CCK-8 were completely abolished. In contrast vagotomy had no effect on responses to supraphysiological levels of CCK-8. Infusion of tetrodotoxin (TTX) $(10 \mu \mathrm{g} / \mathrm{kg}+2 \mu \mathrm{g} /$ $\mathrm{kg}$ per $\mathrm{h}$ ) into the pancreatic artery inhibited $65 \%$ of the pancreatic response to CCK-8 infusion at $80-160 \mathrm{pmol} / \mathrm{kg}$ per $\mathrm{h}$, indicating that supraphysiological levels of CCK act on intrapancreatic neurons and directly on pancreatic acini. ${ }^{*} P<0.0$. 
had little or no effect on responses to supraphysiological levels of CCK-8 ( 80 and 160 pmol/kg per h) (Fig. 3). To demonstrate that we have performed complete vagotomy we studied the effect of 2DG, which has previously been shown to stimulate pancreatic secretion via a vagal cholinergic pathway (15, 16). In intact rats, $2 D G(75 \mathrm{mg} / \mathrm{kg})$ caused an increase of pancreatic protein secretion by $150 \%$ over basal. In rats with truncal vagotomy, there was no increase in pancreatic secretion in response to $2 \mathrm{DG}$ administration.

To investigate the mechanisms responsible for pancreatic response to supraphysiological levels of $\mathrm{CCK}$, we examined the effect of intraarterial infusion of TTX, which exerts total neural blockade. TTX inhibited $65-75 \%$ of the pancreatic responses to CCK-8 infusion at 80 and $160 \mathrm{pmol} / \mathrm{kg}$ per h (Fig. $3)$. In separate studies, we demonstrated that intraarterial administration of TTX completely abolished pancreatic responses to 2DG but had no effect on stimulation evoked by bethanechol, which acted directly on pancreatic acini. These observations indicate that supraphysiological levels of CCK act on intrapancreatic neurons and directly on pancreatic acini to mediate pancreatic enzyme secretion.

Effect of perivagal application of capsaicin. Similar to truncal vagotomy, perivagal application of capsaicin completely abolished pancreatic protein secretion in response to physiological doses of CCK-8 infusion (10, 20, and $40 \mathrm{pmol} / \mathrm{kg}$ per h) but had no effect on the responses to supraphysiological doses ( 80 and $160 \mathrm{pmol} / \mathrm{kg}$ per $\mathrm{h}$ ) (Fig. 4 ). In contrast, we demonstrated that pancreatic protein secretion in response to 2DG stimulation remained intact in rats with perivagal capsaicin treatment, indicating that capsaicin did not affect efferent vagal function (Fig. 5).

Effect of vagal afferent rootlet section. To further demonstrate that vagal afferent pathway mediates CCK's action on pancreatic enzyme secretion, parallel studies with vagal afferent rootlet section were performed. Similar to perivagal application of capsaicin, afferent rootlet section also completely abolished pancreatic responses to physiological doses of CCK$8(10,20$, and $40 \mathrm{pmol} / \mathrm{kg}$ per $\mathrm{h})$ but was ineffective to modify

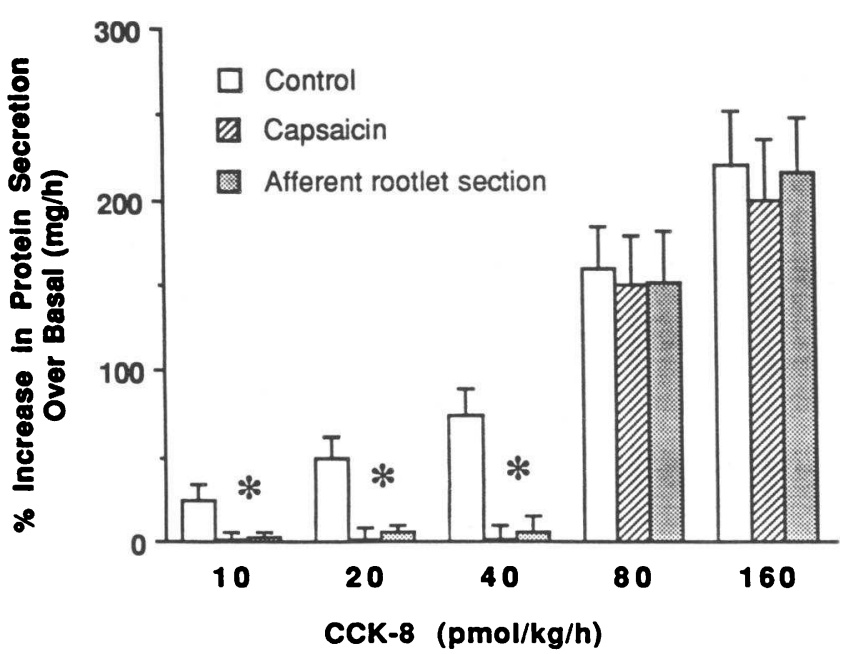

Figure 4. Perivagal application of capsaicin or vagal afferent rootlet section completely abolished the pancreatic responses to physiological doses ( $\leq 40 \mathrm{pmol} / \mathrm{kg}$ per $\mathrm{h}$ ) of CCK-8 but had no effect on the responses to supraphysiological doses. Values are mean $\pm \mathrm{SE}$ for six rats in each group. ${ }^{*} P<0.05$.

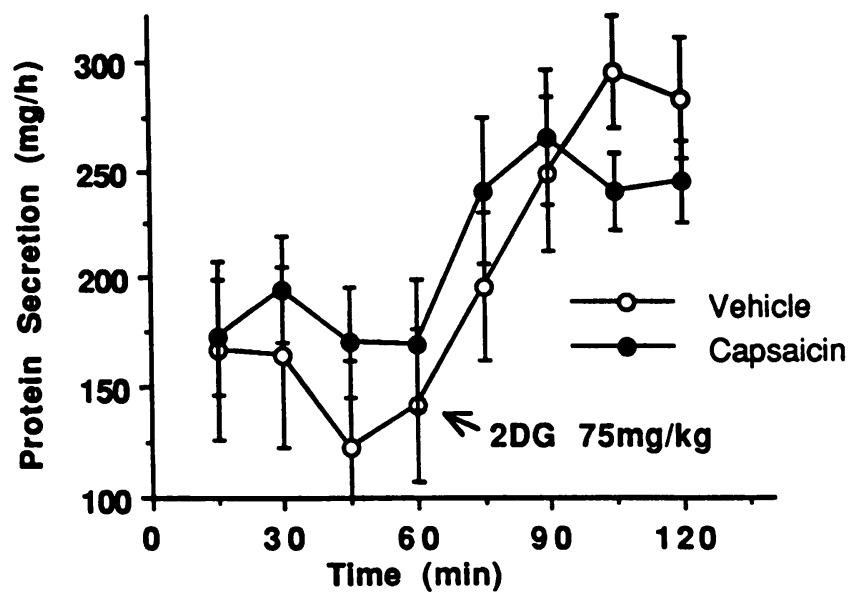

Figure 5. Pancreatic protein responses to 2DG stimulation remained intact in rats with perivagal capsaicin treatment, indicating that capsaicin does not affect efferent vagal function. Values are mean $\pm S E$ for six rats in each group.

the responses to supraphysiological doses of CCK-8 (80 and $160 \mathrm{pmol} / \mathrm{kg}$ per $\mathrm{h}$ ) (Fig. 4).

Effect of gastroduodenal mucosal application of capsaicin. Compared with control, gastroduodenal mucosal application of capsaicin completely abolished pancreatic protein responses to physiological doses of CCK-8 (10,20, and $40 \mathrm{pmol} / \mathrm{kg}$ per h) but had no effect on the responses to supraphysiological doses ( 80 and $160 \mathrm{pmol} / \mathrm{kg}$ per $\mathrm{h}$ ) (Fig. 6). In separate studies we demonstrated that gastroduodenal mucosal application of capsaicin did not affect pancreatic protein responses to stimulation by $2 \mathrm{DG}$, indicating that gastroduodenal administration of capsaicin did not affect efferent vagal transmission or pancreatic acini secretory function.

In contrast to duodenal application of capsaicin, jejunal mucosal application of capsaicin did not affect pancreatic protein responses to both physiological and supraphysiological doses of CCK-8 (Fig. 6).

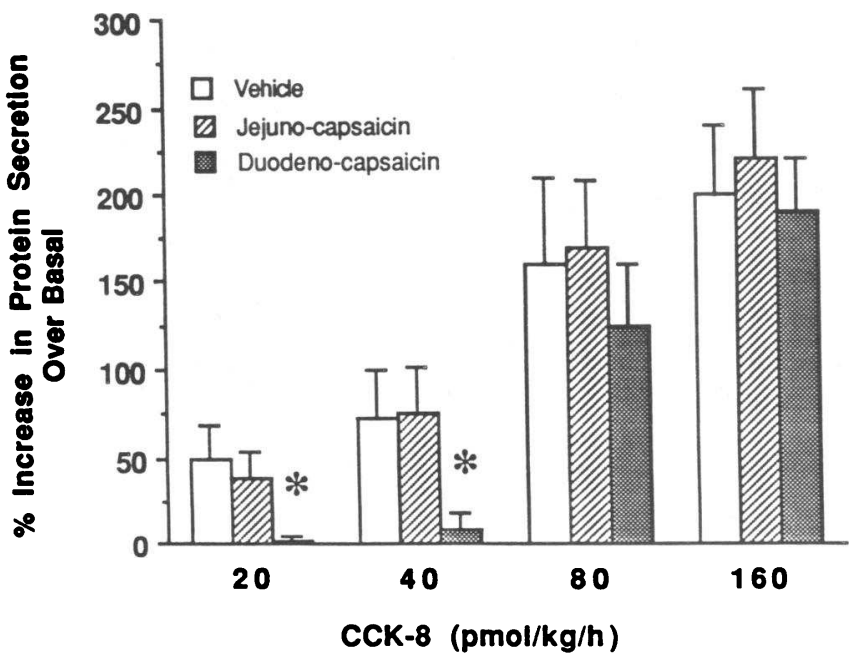

Figure 6. Gastroduodenal mucosal application of capsaicin $(6 \mathrm{mg} / \mathrm{ml}$ for $30 \mathrm{~min}$ ) completely abolished the pancreatic responses to physiological doses ( $\leq 40 \mathrm{pmol} / \mathrm{kg}$ per $\mathrm{h}$ ) of CCK-8 but had no effect on the responses to supraphysiological doses. Values are mean $\pm \mathrm{SE}$ for six rats in each group. ${ }^{*} P<0.05$. 
Effect of bethanechol on CCK-evoked pancreatic secretion in acute vagotomized rats. Intravenous infusion of bethanechol $(0.5 \mathrm{mg} / \mathrm{kg}$ per $\mathrm{h})$ in acute vagotomized rats produced a $65 \%$ increase in pancreatic protein secretion over basal. On the other hand, administration of CCK-8 $(40 \mathrm{pmol} / \mathrm{kg}$ per $\mathrm{h})$ alone failed to stimulate pancreatic secretion in these rats (Fig. 7). Furthermore infusion of CCK-8 also did not evoke additional increase in pancreatic secretion stimulated by bethanechol (Fig. 7). This indicates that failure of CCK-8 given at physiological doses to evoke pancreatic secretion in acute vagotomized rats is not due to absence of cholinergic tone.

\section{Discussion}

The mechanism(s) by which CCK acts to stimulate pancreatic enzyme secretion remains controversial. In this study we investigated the relative roles of neural activation and direct acini stimulation at physiological and supraphysiological levels of CCK using an in vivo rat model. Our results clearly indicate that the sites of CCK's action to stimulate pancreatic secretion are dose dependent. Doses of CCK-8 that produce physiological plasma CCK levels act via stimulation of the vagal afferent pathway, whereas doses that produce supraphysiological CCK levels act to stimulate intrapancreatic neurons and to a lesser degree pancreatic acini. These observations support a predominantly neural physiological role for CCK to stimulate pancreatic enzyme secretion.

In the past a number of investigators were unable to demonstrate inhibition of CCK or CCK-like peptide-evoked pancreatic enzyme secretion with atropine in the $\operatorname{dog}(18,19)$. These studies all used high doses of exogenous CCK and did not assess whether these CCK doses reproduced physiological conditions. On the other hand, Konturek et al. (20), using a canine model, demonstrated that pancreatic enzyme outputs in response to low doses of exogenous CCK was inhibited by atropine, whereas enzyme outputs in response to high doses of

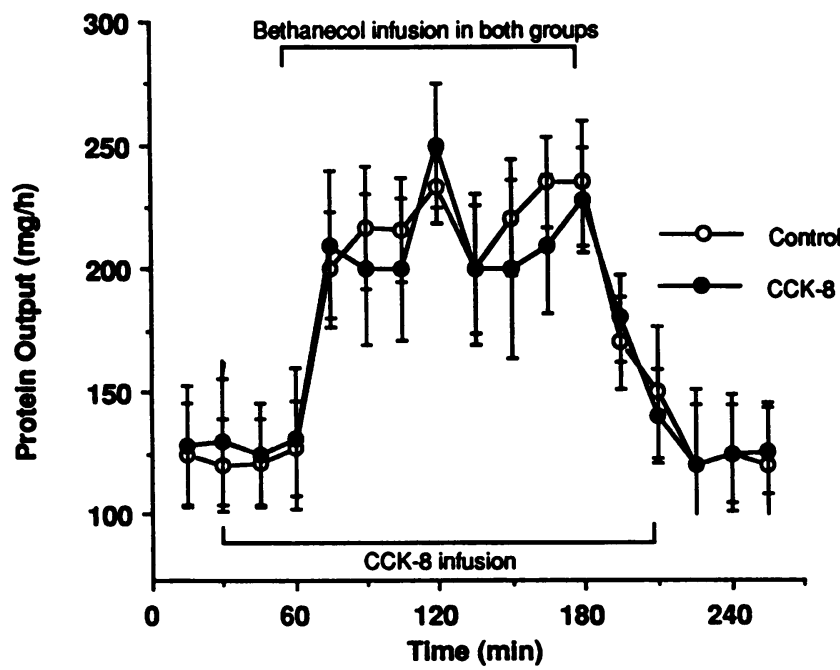

Figure 7. Effect of bethanechol on CCK-8-evoked pancreatic protein secretion in acute vagotomized rats. After acute subdiaphragmatic vagotomy, bethanechol $(0.5 \mathrm{mg} / \mathrm{kg}$ per $\mathrm{h})$ was administered by continuous intravenous infusion for $120 \mathrm{~min}$ in both groups of rats. In one group, CCK-8 ( $40 \mathrm{pmol} / \mathrm{kg}$ per h) was infused $30 \mathrm{~min}$ before bethanechol infusion and continued for a total of $180 \mathrm{~min}$. Values are mean $\pm \mathrm{SE}$ for six rats in each group. No significant difference was observed between the two groups.
CCK were relatively insensitive to atropine. These observations are very much in accordance with our present findings. Unfortunately, in that study, the CCK preparation used was impure and there were no determinations of plasma CCK made in their investigation, therefore, no assessment of physiological relevance could be made. More recently we (5) and others $(6,7)$ have shown that, in humans, CCK infusion that produced plasma CCK levels similar to those seen postprandially stimulated pancreatic secretion by an atropine-sensitive pathway. These observations suggest that in both humans and experimental animals cholinergic neural pathways rather than pancreatic acini represent the primary targets in which CCK acts to stimulate pancreatic enzyme secretion.

Since atropine and hexamethonium completely abolished pancreatic enzyme responses to physiological doses of CCK, it suggests that CCK is acting on a presynaptic site along the cholinergic pathway. To further identify the location of action we examined the effect of bilateral subdiaphragmatic vagotomy. Similar to atropine or hexamethonium, vagotomy completely abolished pancreatic responses to low (physiological) doses of CCK but had little effect on responses to supraphysiological doses of CCK-8. We ruled out the possibility that a basal vagal cholinergic tone is necessary for CCK to directly stimulate pancreatic acinar secretion by showing that CCK did not produce an additional increase in pancreatic secretion stimulated by bethanechol after acute vagotomy (Fig. 7). Our results therefore indicate that CCK stimulates pancreatic secretion via vagal pathway. This observation is supported by previous studies showing reduction in basal and nutrient-stimulated pancreatic secretion after truncal vagotomy $(10,18)$. Additionally, Malagelada et al. (10) reported that pancreatic secretion induced by low but not high doses of CCK is impaired after vagotomy in humans. Furthermore, studies on dogs with denervated autotransplanted pancreas show impaired responsiveness to nutrients (21). Subsequent vagotomy or administration of atropine does not further impair pancreatic responses to nutrient stimuli in this model $(19,21)$. These observations indicate the importance of vagal innervation in the mediation of CCK-evoked pancreatic enzyme secretion. It is important, however, to contrast these findings with some earlier studies that show that vagotomy does not significantly reduce pancreatic enzyme secretion in response to exogenous CCK $(18,21-$ 24). These contradictory findings are likely to be related to the use of supraphysiological doses of CCK in earlier studies and different lengths of time after vagotomy before the experiment begins. In fact our preliminary studies in rats indicate that responsiveness of the pancreas to CCK stimulation returns within $2 \mathrm{wk}$ after vagotomy, possibly because of recruitment of a population of intrapancreatic neurons that were previously unresponsive to physiological concentrations of CCK (unpublished data).

To investigate if CCK exerts its action via an afferent or efferent vagal pathway we examined the effect of perivagal treatment with the sensory neurotoxin capsaicin. Capsaicin is becoming widely used as a tool to investigate the role of afferent $C$-fibers in a number of physiological processes (25). Systemic administration of capsaicin has been shown to affect neurotransmission in all somatic and visceral capsaicin-sensitive fibers. In addition, since capsaicin crosses the blood-brain barrier, systemic administration of capsaicin may also produce effects in the central nervous system. In this study we applied capsaicin directly to the vagal trunks to avoid effects on affer- 
ent terminals in the peripheral and central nervous system. Perivagal application of capsaicin has been shown to inhibit axonal transport of peptides including substance $P$ and somatostatin (26). Previous studies have demonstrated that perivagal capsaicin treatment abolishes the vagal afferent pathway by which CCK increases satiety (11) and decreases gastric emptying (27). We showed that perivagal pretreatment with capsaicin impaired pancreatic responses to physiological doses of CCK-8, an effect similar to that observed with vagotomy or atropine. Similar findings were observed with vagal afferent rootlet section. This indicates that vagal afferent pathway is the primary site of action of CCK. To ensure that capsaicin treatment does not affect efferent vagal function, we demonstrated that pancreatic response to 2DG stimulation remained intact in capsaicin-treated rats. Since pancreatic responses to stimulation by physiological doses of CCK were impaired in these rats, whose efferent vagal function was intact, it argues against CCK acting on vagal efferent pathway to mediate pancreatic secretion. We have previously demonstrated that CCK stimulates acetylcholine release from rat pancreatic lobules, indicating CCK can evoke intrapancreatic cholinergic transmission (5). However the doses of CCK $-8(1 \mu \mathrm{M})$ needed to stimulate intrapancreatic nerves in the lobule preparation were $\geq 10^{6}$ times significantly higher than postprandial levels of CCK, raising questions as to the physiological relevance of this observation. Our current in vivo studies further demonstrated that only supraphysiological levels of CCK act on intrapancreatic neurons to mediate pancreatic enzyme secretion (Fig. 3).

Using combined immunohistochemistry and retrograde tracing, the presence of capsaicin-sensitive afferent nerve fibers has been shown in the gastrointestinal mucosa (28). These neural fibers are known to participate in the regulation of motility, acid secretion, and blood flow $(17,29)$. To further localize the site of action of CCK on the vagal afferent pathway we examined the effect of mucosal application of capsaicin in different regions of the gastrointestinal tract. This technique has been used to chemically denervate sensory fibers in the duodenal mucosa (17). Our studies demonstrated that gastroduodenal application of capsaicin completely abolished pancreatic secretory responses to physiological doses of CCK- 8 but had no effect on the responses to supraphysiological doses. In contrast, jejunal mucosal application of capsaicin did not affect pancreatic responses to CCK-8. These observations indicate that CCK-sensitive afferent fibers originate from the vagal branch from the mucosa of the stomach and duodenum but not from the jejunum.

In conclusion, we have demonstrated that the mechanisms and sites of action of CCK on pancreatic enzyme secretion are dose dependent. Doses of CCK-8 that produce physiological plasma CCK levels act via stimulation of vagal afferent pathway originated from the gastroduodenal mucosa (Fig. 8). In contrast, doses of CCK-8 that produce supraphysiological plasma CCK levels act on intrapancreatic neurons and, to a lesser degree, on pancreatic acini (Fig. 8). These findings have important physiological ramifications. Not only do they explain the discrepancies in previous in vivo versus in vitro studies but they revolutionize our current concept on the mechanism of action of CCK on pancreatic exocrine secretion. Under physiological conditions, cholinergic vagal afferent pathway rather than pancreatic acinar cells represent the primary targets on which CCK may act as a major mediator of postprandial pancreatic enzyme secretion.

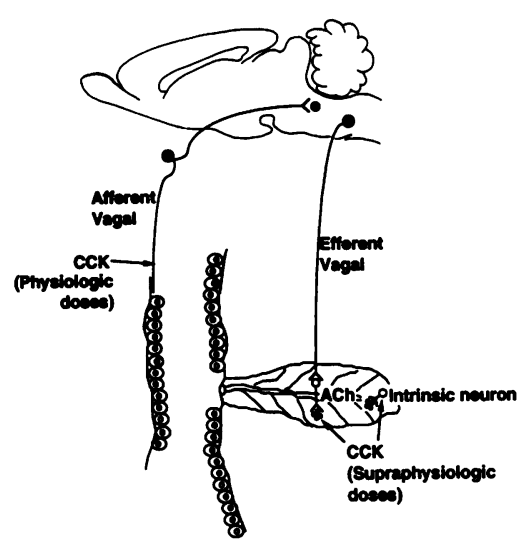

Acknowledgments
Figure 8 . The sites and mechanisms of action of CCK to stimulate pancreatic enzyme secretion. Doses of CCK-8 that produce physiological plasma CCK levels act via stimulation of vagal afferent pathway originated from the gastroduodenal mucosa. In contrast, doses that produce supraphysiological plasma CCK levels act on intrapancreatic neurons and, to a larger extent, on pancreatic acini.
This investigation was supported in part by U.S. Public Health Service grants DK-32838 and P30 DK-34933 from the National Institute of Diabetes, Digestive, and Kidney Disease.

\section{References}

1. Williams, J. A., M. Korc, and R. L. Dormer. 1978. Action of secretagogues on a new preparation of functionally intact, isolated pancreatic acini. Am. J. Physiol. 235:E517-E524.

2. Peikin, S. R., A. J. Rottman, S. Batzri, and J. D. Gardner. 1978. Kinetics of amylase release by dispersed acini prepared from guinea pig pancreas. Am. J. Physiol. 235:E743-E749.

3. Solomon, T. E. 1987. Control of exocrine pancreatic secretion. In Physiology of the Gastrointestinal Tract. L. R. Johnson, editor. Raven Press, New York. 1173-1208.

4. Singer, M. V. 1987. Pancreatic secretory response to intestinal stimulants: a review. Scand. J. Gastroenterol. 22:1-13.

5. Soudah, H., Y. Lu, and C. Owyang. 1992. Physiologic action of CCK on pancreatic enzyme secretion is mediated by a cholinergic pathway. Am. J. Physiol. 263:G102-G107.

6. Guido, A., C. Beglinger, U. Braun, M. Reinshagen, and R. Arnold. 1991. Interaction of the cholinergic system and choleycstokinin in the regulation of endogenous and exogenous stimulation of pancreatic secretion in humans. Gastroenterology. 100:537-543.

7. Bozkurt, T., G. Adler, I. Koop, and R. Arnold. 1988. Effect of atropine on intestinal phase of pancreatic secretion in man. Digestion. 41:108-115.

8. Bommelaer, G., G. Rozental, J. Laval, C. Senarens, N. Vaysse, and A. Ribet. 1980. Regulation of amylase release by dog pancreatic acini. In Biology of Normal and Cancerous Exocrine Pancreatic Cells. A. Ribet, L. Pradayrol, and C. Susini, editors. Elsevier/North Holland, Amsterdam, The Netherlands. 19-25.

9. Inoue, K., G. M. Fried, I. Wiener, X. Zhu, G. H. Greeley, Jr., and J. C. Thompson. 1984. Colonic inhibition of cholecystokinin release and pancreatic protein secretion in dogs. Surg. Gynecol. Obstet. 159:423-428.

10. Malagelada, J. R., V. L. W. Go, and W. H. J. S. Summerskill. 1974. Altered pancreatic and biliary function after vagotomy and pyloroplasty. Gastroenterology. 66:22-27.

11. South, E. H., and R. C. Ritter. 1988. Capsaicin application to central or peripheral vagal fibers attenuates CCK satiety. Peptides (NY) 9:601-612.

12. Bradford, M. A. 1976. Rapid and sensitive method for the quantitation of microgram quantities of protein utilizing the principle of protein dye binding. Anal. Biochem. 72:248-254.

13. Louie, D. S., J. A. Williams, and C. Owyang. 1985. Action of pancreatic polypeptide on rat pancreatic secretion: in vivo and in vitro. Am. J. Physiol. 249:G489-G495.

14. Louie, D. S., D. May, P. Miller, and C. Owyang. Cholecystokinin mediates feedback regulation of pancreatic enzyme secretion in rats. Am. J. Physiol. 250:G252-G259.

15. Putnam, W. S., R. A. Liddle, and J. A. Williams. 1989. Inhibitory regulation of rat exocrine pancreas by peptide YY and pancreatic polypeptide. Am. J. Physiol. 256:G698-G703.

16. Becker, S., W. Biebel, and M. V. Sender. 1988. Nervous control of gastric 
17. Takeuchi, J., J. Matsumoto, K. Ueshima, and S. Okabe. 1991. Role of capsaicin-sensitive afferent neurons in alkaline secretory response to luminal acid in the rat duodenum. Gastroenterology. 101:954-961.

18. Henriksen, F. W. 1969. Effect of vagotomy or atropine on the canine pancreatic response to secretin and pancreozymin. Scand. J. Gastroenterol. 4:137-144.

19. Singer, M. V., T. E. Solomon, and M. I. Grossman. 1980. Effect of atropine on secretion from intact and transplanted pancreas in dog. Am. J. Physiol. 238:G18-G22.

20. Konturek, S. J., J. Tasler, and W. Oftulowicz. 1972. Effect of atropine on pancreatic responses to endogenous and exogenous cholecystokinin. Dig. Dis. Sci. 17:911-917.

21. Solomon, T. E., and M. I. Grossman. 1979. Effect of atropine and vagotomy on response of transplanted pancreas. Am. J. Physiol. 236:E186-E190.

22. Debas, H. T., S. J. Konturek, and M. I. Grossman. 1975. Effect of extragastric and truncal vagotomy on pancreatic secretion in the dog. Am. J. Physiol. 228:1172-1177

23. Konturek, S. J., H. D. Becker, and J. C. Thompson. 1974. Effect of vagotomy on hormones stimulating pancreatic secretion. Arch. Surg. 108:704-708. and pancreatic secretory response to 2-deoxy-D-glucose in the dog. Digestion. 39:187-196.

24. Konturek, S. J., T. Radecki, J. Biernat, and P. Thor. 1972. Effect of vagotomy on pancreatic secretion evoked by endogenous and exogenous cholecystokinin and caerulein. Gastroenterology. 63:273-278.

25. Buck, S. H., and T. F. Burks. 1986. The neuropharmacology of capsaicin: review of some recent observations. Pharmacol. Rev. 38:179-226.

26. Gamse, R., U. Petsche, F. Lembeck, and G. Jancso. 1982. Capsaicin applied to peripheral nerve inhibits axoplasmic transport of substance $P$ and somatostatin. Brain Res. 239:447-462.

27. Raybould, H., and Y. Tache. 1988. Cholecystokinin-8 inhibits gastric motility and emptying by capsaicin sensitive vagal afferent pathways in the rat. Am. J. Physiol. 255:G242-G246.

28. Holzer, P. 1988. Local effector functions of capsaicin-sensitive sensory nerve endings: involvement of tachykinins, calcitronin gene-related and other neuropeptides. Neuroscience. 24:739-768.

29. Lundberg, J. M., E. Brodin, X.-Y. Huz, and A. Saria. Vascular permeability changes and smooth muscle contraction in relation to capsaicin-sensitive substance $\mathrm{P}$ afferents in the guinea pig. Acta. Physiol. Scand. 120:217-227. 